\title{
Strategic Trade Policy Aspects of the Kyoto Protocol: Extracting Oil Rents
}

\author{
Zhihao $\mathrm{Yu}^{\mathrm{a}^{*}}$
}

${ }^{a}$ Carleton University and SHUFE

\begin{abstract}
The paper has identified a unique aspect of the Kyoto Protocol from the perspective of strategic trade and environmental policy. While investigating the horizontal "profit-shifting", vertical "rentextracting", and "collusion-facilitating" effects, it focuses on the strategic behavior of the OPEC and the potential role of the Protocol in extracting oil rent back from the OPEC. It is also shown that even in the absence of environmental considerations, those member countries that export oil could benefit from the Kyoto Protocol. These results shall strengthen the argument for the sustainability of the Kyoto Protocol in the long run.
\end{abstract}

JEL Classification: F18, F12, H4

Keywords: Kyoto Protocol, trade and the environment, strategic trade and environmental policy

\section{Introduction}

One of the most important features of recent international environmental agreements (IEAs) is characterized by self-enforcing and voluntary participation (e.g., see Barrett (1994a), Saijo and Yamato (1999)). To explain these features, the incentives (i.e. the relevant costs and benefits) of their signatories to join such IEAs need to be understood. Moreover, a better understanding of these benefits and costs is also very important for IEAs to be sustained in the long run. The Kyoto Protocol requires a rapid reduction of

* Department of Economics, Carleton University, 1125 Colonel By Drive, Ottawa, Ont. K1S 5B6, Canada; Tel: 1-613-520-2600 ext. 3763; Fax: 1-613-520-3906; Email: zhihao_yu@carleton.ca; Home Page: www. carleton.ca/ zyu. The author wishes to thank Jim Brander, an anonymous referee, and the participants at the 2007 APJAE Symposium on Strategic Trade Theory and Economic Development for helpful comments. Thanks are also extended to Scott Taylor for useful discussion on this topic. An earlier version of this paper was circulated under the title "A Strategic Trade and Environmental Argument for the Kyoto Protocol" (Yu (2001)). The revision was finished during a visit to Shanghai University of Finance and Economics and the author is very grateful for their hospitality. Financial support from the Social Sciences and Humanities Research Council of Canada and 2006 Carlton University Research Achievement Award is also gratefully acknowledged. 
carbon emissions by industrial nations but leaving developing countries sitting on the sideline uncommitted. For example, although India and China have now signed on, they have been given a pass on the first Kyoto round and do not have to begin making emissions cuts until after 2012. However, when the Kyoto Protocol went into effect on 16 February 2005 , it was ratified by 141 countries, including most major industrialized nations except the US and Australia. ${ }^{1}$ The purpose of this paper is to suggest an argument for the Kyoto Protocol from the perspective of strategic trade and environmental policy.

There are two common arguments for the IEAs and international coordination on environmental policy. The first argument is based on the fact that environmental issues are characterized by trans-boundary pollution and the associated free-riding problems. The second argument comes from the fear for the prison's dilemma: in a non-operative game each country might adopt lax environmental policy when it is concerned with the competitiveness of its firms in the world market. This paper, however, identifies a unique aspect of the Kyoto Protocol, which hopefully would not only help us to better understand the incentives of the signatories but also strengthen their future cooperation.

Specifically, notice that a major part of the carbon emissions of most signatories of the industrialized nations in the Kyoto Protocol comes from consumption of oil. Most of these industrialized nations are also oil-importers - except a few countries (e.g. Norway, Britain, and Canada) - and they constitute the major demand in the world oil market. On the supply side of oil, the OPEC is the dominant player in the world market. Because of the collusive behavior among the OPEC countries (through limiting output and hence raising oil price), they earn a huge amount of rents. This suggests that the Kyoto Protocol could potentially play a role of "strategic rent-extraction” (see Brander and Spencer (1984)).

As shown in the paper, however, the effect of such a rent-extracting initiative by one nation is limited due to the product competition in the world market and hence such an incentive is dominated by the concern for the competitiveness of its firms. But the Kyoto Protocol could potentially play the role of coordination for the rent-extracting effect to be achieved. Moreover, this paper shows that having accounted for the strategic behavior of the OPEC, the Kyoto Protocol could even benefit those member countries that actually export oil.

It is well known that the entire burden of an excise tax falls on the supplier when a good is in fixed supply. ${ }^{2}$ In general, if the elasticity of supply of a fuel is low, the producers will bear the most burden of any carbon tax. Most computational-general-equilibrium (CGE) models of economic effects of carbon reductions make little explicit provision for international trade effects (e.g., Manne and Richels (1991)). The first exception is Whalley and Wigle (1991), in which they employ an inelastic world supply curve for all

${ }^{1}$ Canada recently has decided to opt out of the Kyoto Protocol because it cannot reach the target of the first Kyoto round.

${ }^{2}$ Bergstrom (1982) extends this insight to a multi-period framework, in which the total supply of a good is fixed, through imposing such a tax once and forever. 
carbon energy. ${ }^{3}$ But the study does not capture the strategic behaviour of the OPEC. With an inelastic supply, much of the impact of a reduction in demand falls on the price of the fuel, rather than on the level of its use. However, if a fuel is supplied by a major producer that has monopoly power, the supply response would be very different (monopoly does not have a supply curve). It would reduce its output to keep up the price of the fuel. This would reduce the negative impact (i.e., the reduction of price) on other exporters of the fuel. As it is shown in this paper, the Kyoto Protocol could actually benefit those member countries that actually export oil even in the absence of environmental consideration.

The idea of strategic rent-extracting is first illustrated by Brander and Spencer (1984). This paper also benefits from a recent paper by Ishikawa and Spencer (1999) in which these authors analyze the issues of both horizontal profit-shifting and vertical rentextracting under imperfect competition and the implications for strategic trade policy. The literature on strategic environmental policy has focused on the horizontal profit-shifting effect (e.g., see Barrett (1994b), Conrad (1996), Kennedy (1994), and Ulph (1996) rather than the vertical rent-extracting effect as discussed in this paper.

The rest of the paper is organized as follows. Section 2 uses a model of Bertrand competition to highlight the conflict between the rent-extraction and competitiveness consideration. Section 3 uses a model of Cournot competition to analyze in detail the rent-extracting, profit-shifting, collusion-facilitating, and transboundary pollution effect of the Kyoto Protocol. Section 4 concludes the paper.

\section{The Environmental and the Strategic Effect of the Kyoto Protocol - the Case of Bertrand Competition}

To highlight the conflict between the rent-extraction and competitiveness considerations when governments impose carbon taxes, this section analyzes the effects of the Kyoto protocol in the framework of Bertrand competition. The competitiveness of firms is illustrated most starkly under the Bertrand competition: the firm that is negatively affected by an environmental tax will be pushed out of the market due to the intensive price competition.

Throughout the analysis, this paper uses the following structure of the game. In the first-stage a government (or governments) imposes a carbon tax. ${ }^{4}$ In the second stage, the oil producing monopolist/country (i.e. OPEC) decides the price of oil. In the third-stage, firms compete in the product market. Using the sub-game Perfect Nash Equilibrium as the equilibrium concept, the game is solved by backward induction.

${ }^{3}$ They have estimated that oil-exporting countries would lose $18.7 \%$ of their GDP over the period 1990-2030 if national consumption taxes were applied to reduce global carbon emissions by 50\% from the baseline they would otherwise follow (Cline (1992)). For the typical set-up of the CGE models with international trade, see Perroni and Rutherford (1993).

${ }^{4}$ The Kyoto Protocol only sets overall emission targets/quotas for the signatory countries. These countries often apply different policy instruments (e.g. pollution taxes, quotas, tradable pollution permits, etc) to their different industries. Only environmental taxes are discussed since the choice of policy instruments is the research interests of this paper. On the other hand, the discussion in this paper (i.e. IEAs based on pollution taxes) can also be viewed as an alternative to the Kyoto Protocol (i.e. IEAs based on quotas). 


\subsection{Rent-extraction and product market competition}

This section first focuses on the tension between the rent-extraction and competitiveness considerations alone, without introducing environmental issues. Assume that there are $n$ identical countries - all have the same production technologies and labor endowments. In each country there are two industries that produce two homogenous goods, $Y$ and $X$, respectively. Good $Y$ is a numeraire good, which is produced under perfect competition by a CRS technology using labor as the only factor of input. This also implies that trade ensures the wage rate to be the same in these countries, which rules out the difference in the cost of labor for producing good $X$. Good $X$ is produced via a Leontif technology using both labor and oil. ${ }^{5}$ By choice of units, it is assumed that to produce one unit of good $X$ requires one unit of labor and oil. That is, the production function is given by

$$
X=\min \{l, k\}
$$

where $l$ and $k$ are inputs of labor and oil, respectively. Suppose labor is immobile between countries and oil is supplied by a monopolist in the word market (each country will be allowed some oil endowment).

Following Brander and Spencer (1984), it is assumed that in each country good $X$ is produced by one firm and is sold in a "third market" - a "world market" that is outside their domestic markets. Suppose the demand of the world market for good $X$ is given by the following inverse demand function,

$$
P=a-b X
$$

Assuming that the output of each firm is small relative to the total demand, first to be solved is the symmetric equilibrium outcome.

Let $w$ be the wage and $r$ the price of oil. The price $(p)$ and the unit cost $(c)$ of good $X$ are then given by

$$
p=c=w+r
$$

From (2) and (3) the output of good $X$ for each country can be obtained,

$$
x=\frac{a-(w+r)}{n b}
$$

The profit of each firm is zero under Bertrand competition except for the monopolist that produces oil.

${ }^{5}$ It will become clear that allowing substitution between $l$ and $k$ (e.g., Cobb-Douglas function) would strengthen the results. 
Using (4) the demand for oil is obtained as follows:

$$
K=n x=\frac{a-(w+r)}{b} .
$$

For simplicity and without loss of generality, suppose the cost of producing and transporting oil is zero. The profit (or rent) for the oil producing monopolist/country becomes

$$
R=\left[\frac{a-(w+r)}{b}\right] r
$$

Therefore, the price of oil that maximizes the profit of the oil producing monopolist/ country is

$$
\begin{aligned}
r^{*} & =\underset{r}{\arg \max }\left[\frac{a-(w+r)}{b}\right] r \\
& =\frac{a-w}{2}
\end{aligned}
$$

and the level of the profit is

$$
R^{*}=\frac{(a-w)^{2}}{4 b}
$$

Now suppose that country $i$ (independently) imposes a tax $t_{i}$ on consumption of oil in order to extract some rent from the oil monopolist. Thus the unit cost of producing good $X$ for firm $i$ (the firm that produces good $\mathrm{X}$ in country $i$ ) becomes

$$
c^{i}=w+r+t^{i}
$$

which is higher than that of the other competitors in the world market. Under Bertrand competition, this means that firm $i$ will be forced out of the world market and therefore the government in country $i$ cannot extract any rent from the oil monopolist. Due to the pressure of competition at the world market, country $i$ cannot gain anything by imposing a consumption tax on oil and therefore would have no incentives to act alone.

However, if these $n$ countries could coordinate and together impose a consumption tax on oil, they can extract rents from the oil monopolist. Suppose they agree to impose a tax $t$ on consumption of oil. As a result, the unit cost of producing good $X$ for each firm (and hence the price of good $X$ ) becomes

$$
p(t)=c(t)=w+r+t
$$

The total demand for oil now becomes

$$
K(t)=n k(t)=n x(t)=\frac{a-(w+r+t)}{b}
$$

It is easy to show that the best response of the oil producing monopolist/country is to reduce the oil price by $t / 2$ to 


$$
\begin{aligned}
r^{*}(t) & =\underset{r}{\arg \max }\left[\frac{a-(w+r+t)}{b}\right] r \\
& =\frac{a-w-t}{2}
\end{aligned}
$$

As a result, its profit reduces to

$$
R^{*}(t)=\frac{(a-w-t)^{2}}{4 b}
$$

It is straightforward to show that the "optimal tax" that maximizes the revenue for these $n$ countires $[t k(t)$ or $n k(t)]$ is

$$
t^{*}=\frac{a-w}{2}
$$

Substituting (14) into (13), shows that the rent of the oil producing monopolist/ country reduces to,

$$
\begin{aligned}
R^{*}\left(t^{*}\right) & =\frac{\left(a-w-t^{*}\right)^{2}}{4 b} \\
& =\frac{(a-w)^{2}}{16 b},
\end{aligned}
$$

which is only one-fourth of the previous level. The total rent that is captured by these $n$ countries from the oil producing monopolist/country is

$$
n t k(t)=\frac{(a-w)^{2}}{8 b}
$$

which is half of the amount of the original rent and twice as much as that of the current rent of the oil producing monopolist/country.

\subsection{Carbon Emission and Environmental Tax}

To fully investigate the effects of the Kyoto Protocol on the signatory countries, our model has to capture the associated environmental issues (i.e., trans-boundary pollution) and the fact that member countries have oil endowment and some may even export oil. How will the Kyoto Protocol affect those who export oil?

Suppose that consumption of oil (by firms in producing good $X$ ) generates carbon emission, which is transboundary pollution that contributes to global warming. Since pollution abatement is not the focus of this paper, we assume that there is no pollution abatement and that one unit of consumption of oil generates one unit of pollution. Therefore, a reduction of carbon emission is possible only when the consumption of oil is reduced. Suppose governments use a consumption tax (on oil) to achieve this objective (this is equivalent to introducing an environmental tax on output of $\operatorname{good} X$ in our model).

Suppose that each country also has oil endowment, $\bar{k}^{i}(i=1, n)$. The objective of each country therefore is to maximize the sum of the return of its oil endowment and the tax 
revenue on oil consumption, minus the damage due to global pollution. Specifically, the government in country $i$ has the following objective function: ${ }^{6}$

$$
G^{i}=r \bar{k}^{i}+t^{i} k^{i}-D(K), \quad \mathrm{D}^{\prime}(.)>0, \quad \mathrm{D}^{\prime \prime}(.)>0,
$$

where $k^{i}$ is the consumption of oil in country $i$ and $K=\sum k^{i}$ is the global consumption of oil, which also represents the total amount of global pollution in our model.

Assume that each country's oil endowment is small relative to the global demand and the the oil producing monopolist/country acts as the price-leader in the oil market. The equilibrium price of oil, when no country imposes a tax, can be obtained as follows (using (5)):

$$
\begin{aligned}
r^{*} & =\underset{r}{\arg \max }\left[K-\sum_{i=1}^{n} \bar{k}^{i}\right] r \\
& =\frac{a-w}{2}-\frac{b}{2} \sum_{i=1}^{n} \bar{k}^{i}
\end{aligned}
$$

Therefore:

$$
\begin{aligned}
G^{i} & =r * \bar{k}_{i}-D(K) \\
& =\left(\frac{a-w}{2}-\frac{b}{2} \sum_{i=1}^{n} \bar{k}_{i}\right) \bar{k}_{i}-D\left(\frac{a-w}{2 b}\right)
\end{aligned}
$$

Can country $i$ increase its welfare, $G_{i}$, by unilaterally imposing an environmental tax on oil? As discussed above, under Bertrand competition firm $i$ will be priced out of the world market if its country imposes a consumption tax on oil. However, the total output of good $X$ and the world demand for oil do not change (the other $n-1$ countries simply increase their shares). Thus the price of oil and the consumption of oil all stay the same. Since pollution is fully transboundary, the damage of global pollution is also the same. Therefore, country $i$ will not gain anything and hence has no incentives to impose a consumption tax on oil. ${ }^{7}$

Now suppose these $n$ countries can sign an agreement to impose a carbon tax - an environmental tax $t$ on oil - in order to reduce carbon emission. As discussed above, the oil producing monopolist/country will in turn reduce the price of oil by $t / 2$. That is

$$
r^{*}(t)=\frac{a-w}{2}-\frac{b}{2} \sum_{i=1}^{n} \bar{k}^{i}-\frac{t}{2}
$$

Welfare for each country now becomes $(i=1, n)$

$$
G^{i}(t)=r^{*}(t) \bar{k}^{i}+t k^{i}-D(K(t))
$$

${ }^{6}$ The profit of its firm producing good $X$ should also be included, which is zero under Bertrand competition, however.

${ }^{7}$ Notice that this is true for any country regardless whether it is an importer or exporter of oil (i.e., $k^{i}-\bar{k}^{i}>0$ or $<0$ ). 
Taking derivative with respect to $t$, it is shown that,

$$
\frac{d G^{i}(t)}{d t}=\bar{k}^{i} \frac{d r}{d t}+\left(k^{i}+t \frac{d k^{i}}{d t}\right)-D^{\prime}(.) K^{\prime}(t)
$$

To evaluate each country's incentive to join a treaty to impose a carbon tax, (22) is evaulated at $t=0$, which is (after substituting (11) and (20) into (22)):

$$
\left.\frac{d G^{i}(t)}{d t}\right|_{t=0}=-\frac{\bar{k}^{i}}{2}+k^{i}+\frac{D^{\prime}(K)}{2 b}
$$

The first term is the "endowment effect", which is negative. An environmental tax on oil reduces the price of oil and hence reduces the income from oil endowment. The second term is the "rent-extracting effect", which is positive. By imposing an environmental tax on oil, these countries can shift some of the oil rents from the oil producing monopolist/ country into their treasuries (tax revenues). The last term is the "environmental effect", which is positive. As a result of the tax, the consumption of oil and the global pollution are reduced.

Equation (23) deserves further discussion. First, since global warming is transboundary pollution, the Kyoto Protocol is helpful for the participating countries to deal with the negative externality of global warming. Second, although the presence of oil endowment in each country would reduce its incentive to join the Kyoto Protocol, the rent-extracting effect of the Kyoto Protocol might be high. In addition to the environmental consideration for cooperation (i.e., $D^{\prime}(K)=0$ ) ), countries (even those that export oil (i.e., $\left.\bar{k}^{i}>k^{i}\right)$ ) would benefit from the Kyoto agreement as long as their oil endowments are not very large relative to their demand (i.e., $k^{i}>2 k^{i}$ ).

\section{The Environmental and the Strategic Effect of the Kyoto Protocol - the Case of Cournot Competition}

The effect of one country's unilateral environmental tax on oil on the competitiveness of its firm in the world market is illustrated starkly under the Bertrand competition in the previous section. A unilateral environmental tax on oil by a government would push its firm out of the world market. This section considers Cournot competition and investigate in more details the rent-extracting, profit-shifting, collusion-facilitating, and transboundary pollution effect.

\subsection{Firm profits vs. the rent of oil}

This subsection first illustrates, using the simplest set-up, how the monopoly power in the oil market could capture firms' profits from the goods market. Suppose that governments do not impose any tax on oil. Then each firm maximizes the following objective function:

$$
\max _{x^{i}} \pi^{i}=\left(a-b \sum_{i=1}^{n} x^{i}\right) x^{i}-(w+r) x^{i}, i=1, n .
$$


The associated first-order condition is

$$
\pi_{i}^{i}=\left(a-b \sum_{i=1}^{n} x^{i}\right)-b x^{i}-(w+r)=0, \quad i=1, n .
$$

The second-order condition for maximization is $\pi_{i i}^{i}<0(i=1, n)$. When the other regularity conditions for the equilibrium are satisfied, the symmetric equilibrium outcome can be obtained for each firm's output and profit:

$$
x=x^{i}=\frac{a-w-r}{(n+1) b}, \forall \mathrm{i}
$$

and

$$
\pi=\pi^{i}=\frac{(a-w-r)^{2}}{(n+1)^{2} b}, \forall \mathrm{i}
$$

First to be calculated is the benchmark case in which the oil market is perfectly competitive. With a perfectly competitive market for oil, the price of oil is equal to the marginal cost of producing oil. To avoid a zero price for oil, it is now assumed that the marginal cost of producing oil is a constant, $c_{0}{ }^{8}$ Therefore, $r=c_{0}$ and the total profits of these oligopolies are

$$
\bar{\Pi}=n \pi=\frac{n\left(a-w-c_{o}\right)^{2}}{(n+1)^{2} b}
$$

To highlight how the monopoly power in the oil market could capture some of the profits from the product market, it is supposed that oil is supplied by a oil producing monopolist/country and other countries do not have any oil endowment. Therefore, the oil producer chooses $r$ to maximize the following:

$$
\max _{r} R=\left(r-c_{o}\right) \frac{n(a-w-r)}{(n+1) b},
$$

since the demand for oil is (recall $K=X$ )

$$
K=\frac{n(a-w-r)}{(n+1) b} \text {. }
$$

Solving (29), the following is obtained:

$$
r^{*}=\frac{a-w+c_{o}}{2}
$$

Therefore, the rent that the oil producing monopolist/country gains from controlling the price (or output) of oil is

$$
R^{*}=\frac{n\left(a-w-c_{o}\right)^{2}}{4(n+1) b}
$$

${ }^{8}$ In Section 2 with Bertrand competition, since the case of a perfectly competitive market for oil is not considered, zero marginal cost of producing oil is assumed. 
As a result, the total profits of these firms reduce to

$$
\underline{\Pi}=\frac{n\left(a-w-c_{o}\right)^{2}}{4(n+1)^{2} b}
$$

Notice that $\underline{\Pi}=\bar{\Pi} / 4$. They have lost three quarters of the total profits in the product market.

The rest of this section shows that an environmental tax on consumption of oil can extract back some of the rent from the oil monopolist and we will focus on the extent of such effects of imposing a tax in the non-cooperative and cooperative environment, respectively. Since the insight of this analysis will still be preserved, $n=2$ is assumed for the rest of the analysis to avoid the unnecessary mathematical complication. But the implications of the results for the general $n$-country case will be discussed.

\subsection{Non-cooperative environmental tax}

Suppose that two countries non-cooperatively impose an environmental tax, $t^{1}$ and $t^{2}$, on consumption of oil. Then, firm $i$ 's profit becomes:

$$
\max _{\mathrm{x}^{i}} \pi^{i}=\left(a-b \sum_{j=1}^{2} x^{j}\right) x^{i}-\left(w+r+t^{i}\right) x^{i}, \quad i, j=1,2 .
$$

The first-order condition that maximizes the profit is

$$
\pi_{i}^{i}=\left(a-b \sum_{j=1}^{2} x^{j}\right)-b x^{i}-\left(w+r+t^{i}\right)=0, \quad i, j=1,2 .
$$

The second-order condition for maximization is $\pi_{i i}^{i}<0(i=1,2)$. It is easy to show that the regularity conditions for the equilibrium are satisfied for the linear demand function. The equilibrium outcomes can be summarized by

$$
x^{i}\left(t^{i}, t^{j}\right) ; \pi^{\mathrm{i}}\left(x^{i}\left(t^{i}, t^{j}\right), x^{j}\left(t^{i}, t^{j}\right), t^{i}\right) . \quad i, j=1,2 .
$$

It is easy to show that $d x^{i} / d t^{i}<0, d x^{i} / d t^{j}>0$.

Summing (35) over $i$ and noticing that $X=\sum_{i=1}^{2} x^{i}$, the following is obtained:

$$
2(a-b X)-b X-2(w+r)+\left(t^{1}+t^{2}\right)=0
$$

The demand for oil therefore is (recall $K=X$ and $k^{i}=x^{i}$ ),

$$
K=\frac{2(a-w-r)-\left(t^{1}+t^{2}\right)}{3 b}
$$

Similar to the previous section, assume that each country's endowment of oil $\left(\bar{k}^{1}\right.$ and $\left.\bar{k}^{2}\right)$ is small relative to the total demand and the oil producing monopolist/country acts as the price-leader in the oil market. The optimization problem for the oil producing monopolist/country becomes:

$$
\max _{r} R=\left(r-c_{o}\right)\left[\frac{2(a-w-r)-\left(t^{1}+t^{2}\right)}{3 b}-\sum_{i=1}^{2} \bar{k}^{i}\right],
$$


Solving (38) gives

$$
r^{*}\left(\sum_{i=1}^{2} t^{i}\right)=\frac{2\left(a-w+c_{o}\right)-\left(t^{1}+t^{2}\right)}{4}-\frac{3 b}{4} \sum_{i=1}^{2} \bar{k}^{i}
$$

Now suppose that pollution is not fully-transboundary. The emission that country $i$ receives is ${ }^{9}$

$$
\begin{aligned}
E^{i} & =k^{i}+\delta \sum_{\mathrm{j} \neq \mathrm{i}}^{2} k^{i} \text { or } \\
& =(1-\delta) k^{\mathrm{i}}+\delta K, \quad 0<\delta<1, \quad i=1,2 .
\end{aligned}
$$

Since under Cournot competition firms also earn profits from the product market, the objective function for governments becomes:

$$
G^{i}=\pi^{i}+r^{*}(t) \bar{k}^{i}+t^{i} k^{i}-D\left(E^{i}\right), i=1,2 .
$$

The first-order condition with respect to $t_{i}$ is

$$
\begin{aligned}
G_{i}^{i}= & {\left[\frac{\partial \pi^{i}}{\partial t^{i}}+\frac{\partial \pi^{i}}{\partial x^{j}} \frac{d x^{j}}{d t^{i}}+\frac{\partial \pi^{i}}{\partial r} \frac{d r}{d t^{i}}\right]+\bar{k}^{i} \frac{d r}{d t^{i}} } \\
& +\left(x^{i}+t^{i} \frac{d x^{i}}{d t^{i}}\right)-D^{\prime}\left(E^{i}\right) \frac{d E^{i}}{d t^{i}}=0, \quad i=1,2 .
\end{aligned}
$$

Assume that the second-order and regularity conditions for maximizaiton are satisfied.

To evaluate the effect of unilaterally imposing a non-cooperative environmental tax on oil, $t^{i}=0$ is set in (42). Using (34) and the envelope theorem, the following is obtained:

$$
\left.G_{i}^{i}\right|_{t^{i}=0}=\underbrace{\frac{\partial \pi^{i}}{\partial x^{j}} \frac{d x^{j}}{d t^{i}}}_{(-)} \underbrace{-k^{i} \frac{d r}{d t^{i}}}_{(+)}+\underbrace{\bar{k}^{i} \frac{d r}{d t^{i}}}_{(-)} \underbrace{-D^{\prime}\left(E^{i}\right) \frac{d E^{i}}{d t^{i}}}_{(+)}
$$

The first term is the "profit-shifting effect", which is not present in the previous section since firms' profits are zero under Bertrand competition. This term is negative since $\frac{\partial \pi^{i}}{\partial x^{j}}<0$ and $\frac{d x^{j}}{d t^{i}}>0$. The intuition is straightforward. A tax on oil in country $i$ will increase the marginal cost of production for firm $i$ and hence reduce firm $i$ 's equilibrium output. Since $x^{i}$ and $x^{j}$ are strategic substitutes under Cournot competition, $x^{j}$ goes up, which leads to a reduction of firm $i$ 's market share and profits. In contrast, a lower tax can shift profits from foreign to domestic firms. Therefore, the profit-shifting effect provides governments with a negative incentive to impose an environmental tax on oil. Notice that if there is an $n$-country case, as in the previous

\footnotetext{
${ }^{9}$ When pollution is fully-transboundary (i.e., $\delta=1$ ), $E_{i}=K$.
} 
section, the (negative) profit-shifting effect becomes stronger because the first term in (43) would become

$$
\sum_{j \neq i}^{n} \frac{\partial \pi^{i}}{\partial x^{j}} \frac{d x^{j}}{d t^{i}}, \quad i, j=1, n .
$$

The second term is the "rent-extracting effect", which is positive. An environmental tax on oil reduces the demand for oil, which in turn forces the oil monopolist to reduce the price of oil. ${ }^{10}$ Thus an environmental tax on oil would reduce rents for the monopolist and increase profits for product producers. Therefore, the rent-extracting effect gives governments a positive incentive to impose an environmental tax on oil. Notice that in an $n$-country case, the (positive) rent-extracting effect would be smaller since (39) becomes

$$
r^{*}\left(\sum_{i=1}^{n} t^{i}\right)=\frac{n\left(a-w+c_{o}\right)-\left(\sum_{i=1}^{n} t^{i}\right)}{2 n}-\frac{3 b}{2 n} \sum_{i=1}^{n} \bar{k}^{i}
$$

and this gives $d r / d t^{i}=1 /(2 n)$. Therefore, the effect of a non-cooperative tax on the reduction of oil price becomes smaller when the number of countries becomes larger.

The third term is the "endowment effect", which is negative. Similarly, this effect would be smaller in an $n$-country case since the effect of a non-cooperative tax on the reduction of the oil price becomes smaller.

The last term is the "environmental effect", which is positive. Using (40) the following can be obtained:

$$
\frac{d E^{i}}{d t^{i}}=\frac{d x^{i}}{d t^{i}}+\delta \frac{d x^{j}}{d t^{i}}, i=1,2
$$

When country $i$ imposes/increases a tax $t^{i}$ on oil, it will reduce the domestic consumption of oil and carbon emission. But unless $\delta=0$ (i.e., pollution is purely local), this effect is mitigated by the fact that the firm in the foreign country increases its consumption of oil and carbon emission. This is due to the strategic interaction among firms that compete in the world market. Firm $j$ increases its output in reaction to the reduction of $x^{i}$ (i.e., $\left.d x^{j} / d t^{i}>0\right)$. However, it can be shown that the total output still becomes lower (i.e., $d X / d t^{i}<0$, where $X=x^{i}+x^{j}$ ), which means,

$$
\begin{aligned}
\frac{d E^{i}}{d t^{i}} & =\frac{d x^{i}}{d t^{i}}+\delta \frac{d x^{j}}{d t^{i}} \\
& =(1-\delta) \frac{d x^{i}}{d t^{i}}+\delta \frac{d X}{d t^{i}}<0, \quad i, j=1,2 .
\end{aligned}
$$

\footnotetext{
${ }^{10}$ Since the direct effects of the tax on government tax revenue and the profit of the domestic firm cancel with each other, the rent-extracting effect in this section is the effect of a reduction of oil price (due to the tax) on the profit of the domestic firm. In the previous section, the rent-extracting effect is on the government tax revenue only.
} 
Therefore, the environmental effect is positive but is likely to be small. In an $n$-country case this effect would become smaller since (44) becomes

$$
\frac{d E^{i}}{d t^{i}}=\frac{d x^{i}}{d t^{i}}+\delta \sum_{j=1, j \neq i}^{n} \frac{d x^{j}}{d t^{i}}, \quad i=1, n .
$$

Therefore, in a non-cooperative environment, the profit-shifting effect might be strong relative to the others. This certainly becomes more likely when the number of countries becomes larger. If $G_{i}^{i}<0$ at $t^{i}=0$, country $i$ has no incentives to impose a non-cooperative tax on oil.

If $G_{i}^{i}>0$ at $t^{i}=0(i=1,2)$, there will be a positive non-cooperative environmental tax on oil, $t^{i n}$, and it is implicitly determined by the following set of equations:

$$
t^{i n}:\left[\frac{\partial \pi^{i}}{\partial t^{i}}+\frac{\partial \pi^{i}}{\partial x^{j}} \frac{d x^{j}}{d t^{i}}+\frac{\partial \pi^{i}}{\partial r} \frac{d r}{d t^{i}}\right]+\left(x^{i}+t^{i} \frac{d x^{i}}{d t^{i}}\right)-D^{\prime}\left(E^{i}\right) \frac{d E^{i}}{d t^{i}}=0, i=1,2
$$

Assuming a symmetric case, this gives $t^{n} \equiv t^{1 n}=t^{2 n}$.

The next section will examine the effects of cooperatively imposing an environmental tax on oil and compare them with the results obtained in this section.

\subsection{Cooperative Environmental Tax}

Now suppose that these two countries could sign a treaty to impose a common tax on consumption of oil, $t$, an environmental tax to combat carbon emission. The first-order conditions corresponding to (35) become

$$
\pi_{i}^{i}=\left(a-b \sum_{j=1}^{2} x^{j}\right)-b x^{i}-(w+r+t)=0, \quad i, j=1,2 .
$$

It is straightforward to obtain that [similar to (26)]

$$
x^{i}(t)=\frac{a-w-r-t}{3 b}, \quad \forall \mathrm{i}
$$

Notice that now $d x^{i} / d t<0(i=1,2)$ with a cooperative environmental tax. The equilibrium profits are $\pi^{i}\left(x^{i}(t, t), x^{j}(t, t), t\right)$ or simply, $\pi^{i}\left(x^{i}(t), x^{j}(t), t\right)$.

The demand for oil therefore is

$$
K(t)=\frac{2(a-w-r-t)}{3 b} .
$$

The price of oil set by the oil producing monopolist/country is given by

$$
r^{*}(t)=\frac{\left(a-w+c_{o}-t\right)}{2}-\frac{3 b}{4} \sum_{i=1}^{2} \bar{k}^{i} .
$$


Therefore the government objective function becomes,

$$
G^{i}=\pi^{i}+r^{*}(t) \bar{k}^{i}+t^{i} k^{i}-D\left(E^{i}\right), i=1,2 .
$$

The first-order condition with respect to $t$ is

$$
\begin{aligned}
\frac{d G^{i}}{d t}= & {\left[\frac{\partial \pi^{i}}{\partial t}+\frac{\partial \pi^{i}}{\partial x^{j}} \frac{d x^{j}}{d t}+\frac{\partial \pi^{i}}{\partial r} \frac{d r}{d t}\right]+\bar{k}^{i} \frac{d r}{d t} } \\
& +\left(x^{i}+t \frac{d x^{i}}{d t}\right)-D^{\prime}\left(E^{i}\right) \frac{d E^{i}}{d t}=0, \quad i=1,2 .
\end{aligned}
$$

When $t=0$ :

$$
\left.\frac{d G^{i}}{d t}\right|_{t=0}=\underbrace{\frac{\partial \pi^{i}}{\partial x^{j}} \frac{d x^{j}}{d t}}_{(+)} \underbrace{-k^{i} \frac{d r}{d t}}_{(+)}+\underbrace{\bar{k}^{i} \frac{d r}{d t}}_{(-)} \underbrace{-D^{\prime}\left(E^{i}\right) \frac{d E^{i}}{d t}}_{(+)}
$$

The first term in (53) looks similar to that in (43) in the case of a noncooperative environmental tax but it actually is positive rather than negative. Instead of the profit-shifting effect of the non-cooperative tax, the cooperative environmental tax on consumption of oil has a "collusion-facilitating effect". "This is very important. When governments impose a common environmental tax on oil, they eliminate the strategic effect on the product market. Instead of $d x^{j} / d t^{i}>0 \forall i$ as in the previous case, there is now $d x^{j} / d t^{i}<0$. Since firms already produce too much in the product market, a common environmental tax on oil effectively facilitates collusion through reducing output of all firms.

The second term is still the "rent-shifting effect" but it is twice as large as that in the case with non-cooperative taxes. Using (39) can show that $d r / d t=-(1 / 2)$ in (53) but $d r / d t^{i}=-(1 / 4)$ in (43). In an $n$-country case the difference would be even greater since $d r / d t^{i}=-[1 /(2 n)]$. The effect of a cooperative tax on the reduction of oil price is much greater than that of a non-cooperative tax. Similar to the rent-extracting effect, the negative "endowment effect" (the third term) also becomes larger with a cooperative environmental tax.

The last term is the "environmental effect" but it is also much greater than that in the case with non-cooperative environmental taxes. Since a common environmental tax eliminates the strategic effect in output and reduces the output of all firms, the pollution reduction is more effective. Notice that this effect would be much stronger in an $n$-country case since

$$
\frac{d E^{i}}{d t}=\frac{d x^{i}}{d t}+\delta \sum_{j=1, j \neq i}^{n} \frac{d x^{j}}{d t}, \quad i=1, n .
$$

\footnotetext{
${ }^{11}$ In Section 2 there is no "collusion-facilitating" effect because profits are zero in Bertrand equilibrium.
} 
Compared with (46) in the previous section, the second term is negative instead of positive.

The collusion-facilitating effect, the rent-shifting effect and the environmental effect (except the endowment effect) all provide governments with positive incentives to cooperatively impose environmental taxes on consumption of oil. Therefore, as long as a country does not have a very large endowment of oil (though it can also be an exporter of oil), it would benefit from the Kyoto agreement.

To compare with the previous section, it can also be shown that

$$
\left.\frac{d G^{i}}{d t}\right|_{t=0}>\left.\frac{d G^{i}}{d t^{i}}\right|_{t^{i}=0} .
$$

That is, the benefits of imposing a cooperative environmental tax are much greater than a non-cooperative tax and this is true even when the impact of carbon emission on the global environment is not taken into account.

The cooperative environmental tax on oil in a symmetric equilibrium, $t^{c}\left(t^{c} \equiv t^{1 c}=t^{2 c}\right)$, is implicitly given by the following equation:

$$
t^{c}: \quad\left[\frac{\partial \pi^{i}}{\partial t}+\frac{\partial \pi^{i}}{\partial x^{j}} \frac{d x^{j}}{d t}+\frac{\partial \pi^{i}}{\partial r} \frac{d r}{d t}\right]+\left(x^{i}+t \frac{d x^{i}}{d t}\right)-D^{\prime}\left(E^{i}\right) \frac{d E^{i}}{d t}=0, i=1,2
$$

It is not difficult to show that $t^{c}=t^{u}$, ceteris paribus.

\section{Concluding Remarks}

This paper has identified a unique aspect of the Kyoto Protocol from the perspective of strategic trade and environmental policy. It focuses on the strategic behavior of the OPEC and the potential role of the Protocol in extracting some of the oil rent back from the OPEC. Recently, there is emerging interest in discussing the need to form the Organization of Petroleum Importing Countries (OPIC). For example, according to Prabhakar Deshpande, ${ }^{12}$ even a small reduction of demand for oil from the oil importing countries could have a strong impact on reducing the price for oil worldwide. Although the current paper is only a theoretical (rather than a formal computational-general-equilibrium) analysis, it highlights the potential strategic role of the Protocol in overcoming the negative incentives of the member countries for reducing their consumption for oil. ${ }^{13}$ The result that those member countries that export oil can also benefit from the Kyoto Protocol even in the absence of environmental consideration is interesting. These results shall strengthen the argument for the sustainability of the Kyoto Protocol in the long run.

\footnotetext{
${ }^{12}$ See http://ssrn.com/abstract=439680.
}

${ }^{13}$ In this simple model, however, the substitution effect between different energies (e.g. coal) on the demand for oil was not considered. Restrictions on carbon emission by the Kyoto Protocol may cause a substitution of oil for coal. This would increase the demand for oil and could become important in the long run. 


\section{References}

Barrett, S., 1994a, "Self-Enforcing International Environmental Agreements," Oxford Economic Papers, 46, 878-894.

Barrett, S., 1994b, “Strategic environmental policy and international trade”, Journal of Public Economics, 54, 325-338.

Bergstrom, T.C., 1982, “On capturing oil rents with a national excise tax”, American Economic Review, 72(1), 194-201.

Brander, J.A. and B.J. Spencer, 1984, “Trade warfare: tariffs and cartels”, Journal of International Economics, 16, 227-242.

Cline, W., 1992, The Economics of Global Warming, Institute for International Economics, Washington DC.

Conrad, K., 1996, “Optimal environmental policy for oligopolistic industries under intra-industry trade” in Environmental Policy and Market Structure, C. Carraro, Y. Katsoulacos, and A. Xepapadeas (ed), Kluwer Academic Publishers, London.

Ishikawa, J. and B.J. Spencer, 1999, "Rent-shifting export subsidies with an imported intermediate product", Journal of International Economics, 48, 199-233.

Kennedy, P., 1994, "Equilibrium pollution taxes in open economies with imperfect competition", Journal of Environmental Economics and Management 27, 49-63.

Manne, A.S. and R.G. Richels, 1991, "Global C02 emission reductions: the impacts of rising energy costs," The Energy Journal, 12, 87-107.

Perroni C. and T.F. Rutherford, 1993, "International Trade in Carbon Emission Rights and Basic Materials: General Equilibrium Calculations for 2000," Scandinavian Journal of Economics 95(3), 257-278.

Saijo T. and T. Yamato, 1999, "A voluntary participation game with a non-excludable public good", Journal of Economic Theory, 84, 227-242.

Ulph, A., 1996, "Environmental policy and international trade when governments and producers act strategically", Journal of Environmental Economics and Management 30(3), 265-281.

Whalley J. and R. Wigle, 1991, “The International Incidence of Carbon Taxes,” in Global Warming: Economic Policy Responses, R. Dornbusch and J.M. Poterba (eds), MIT Press, Cambridge, 233-263.

Yu, Z. 2001, "A Strategic Trade and Environmental Policy Argument for the Kyoto Protocol,” GEP Research Papers No. 2001/09, University of Nottingham. 